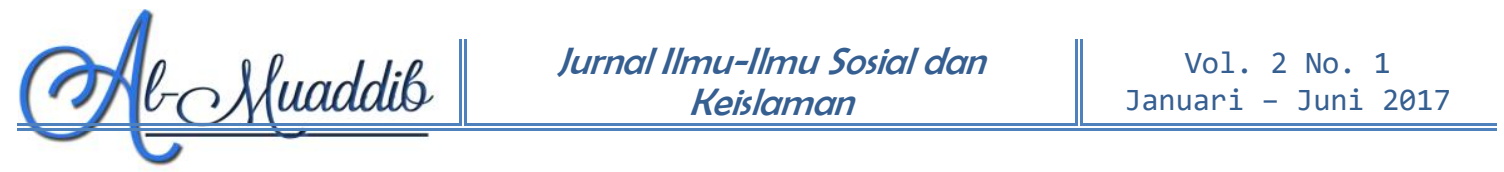

\title{
UPAYA PENINGKATAN PRESTASI BELAJAR PENDIDIKAN AGAMA ISLAM DENGAN MENERAPKAN METODE JIGSAW LEARNING PADA SISWA KELAS V SD NEGERI 0701 ROTAN SOGO
}

\author{
Oleh: \\ Roslina Nasution \\ SD Negeri 0718 Pir Trans Sosa I B \\ roslinanasution1@gmail.com
}

\begin{abstract}
This study is an effort to increase learning achievement by applying the jigsaw learning method on Elementary School fifth grade students of Rattan Sogo 0701. By applying the jigsaw learning method is expected to improve the quality of teaching so that an increase learning achievement. Design of this research is the subject of action by the Elementary School fifth grade students of Rattan Sogo 0701. Collecting data in this study done by observation and written tests individuals and groups at the end of the lesson. Data obtained from each cycle were analyzed with descriptive qualitative and quantitative. The results showed that increased student involvement which have an impact on student achievement has increased after a study carried out by applying jigsaw learning method, with the following results: in the first cycle the average value of 6.21 grade increased to 6.72 in the second cycle and more increased again in the third cycle becomes 8.24
\end{abstract}

\section{Keywords: academic achievement, methods jigsaw Learning}

\section{A. PENDAHULUAN}

Pendidikan adalah suatu hal yang penting dan mutlak bagi manusia, melalui pendidikan manusia mengembangkan kemampuan dan kepribadiannya. Bentuk kongkret dari pendidikan yang dilakukan manusia tersebut tampak dalam aktifitas pembelajaran sebagaimana Sudjana (1989:23) mengatakan bahwa proses pembelajaran merupakan suatu kegiatan untuk mencapai tujuan pendidikan yang telah ditetapkan.

Pembelajaraan merupakan suatu kegiatan yang melibatkan seseorang dalam upaya memperoleh pengetahuan, ketrampilan dan nilai-nilai positif dengan memanfaatkan berbagai sumber untuk 
belajar. Dalam kegiatan pembelajaran ini menunjuk pada kegiatan yang didalamnya terdapat integrasi dan interaksi komponen-komponen pembelajaran yang dapat dikategorikan menjadi tiga hal pokok yaitu guru, materi pelajaran dan siswa. Interaksi antara tiga komponen utama melibatkan sarana dan prasana seperti metode pembelajaran, media pembelajaran, setting kelas sehingga tercipta situasi pembelajaran yang memungkinkan tercapainya tujuan yang telah direncanakan.

Guru seyogyanya mampu menentukan metode pembelajaran yang dipandang dapat membelajarkan siswa secara aktif melalui proses pembelajaran yang dilaksanakan agar tujuan pembelajaran dapat tercapai secara efektif dan hasil belajar dalam kegiatan pembelajaran adalah terjadinya proses belajar (learning proses) pada diri siswa.

Proses pembelajaran yang dilakukan oleh sebagian besar guru masih ada yang cenderung pada pencapaian target materi kurikulum, lebih mementingkan pada penghafalan konsep bukan pada pemahaman. Hal ini dapat dilihat dari kegiatan pembelajaran di dalam kelas yang selalu didominasi oleh guru. Dalam penyampaian materi, biasanya guru menggunakan metode yang monoton seperti metode ceramah, dimana siswa hanya duduk, mencatat, dan mendengarkan apa yang disampaikannya dan sedikit peluang bagi siswa untuk bertanya, sehingga siswa merasa jenuh dalam mengikuti proses pembelajaran. Dengan demikian, suasana pembelajaran menjadi tidak kondusif karena siswa menjadi pasif.

Kondisi seperti itu terjadi pula pada kegiatan pembelajaran mata pelajaran Pendidikan Agama Islam di kelas V SD Negeri 0701 Rotan Sogo Kecamatan Hutaraja Tinggi Kabupaten Padang Lawas. Kondisi awal kegiatan belajar mengajar di kelas tersebut untuk mata pelajaran Pendidikan Agama Islam menunjukkan hasil belajar siswa rendah dan belum mencapai kriteria ketuntasan belajar (KKM), ini dapat dilihat dari 33 siswa, 17 orang siswa atau 50 \% siswa kelas V nilainya kurang 
dari 65 sebagai batas KKM. Hasil refleksi diri menunjukkan bahwa rendahnya prestasi belajar tersebut diantaranya sikap pasif siswa dalam proses pembelajaran, proses pembelajaran yang kurang bervariasi dan monoton, dominasi guru masih sangat besar sehingga siswa kurang mandiri yang berpengaruh terhadap prestasi belajar. dilakukan oleh guru untuk lebih mengaktifkan belajar siswa di kelas yaitu dengan menggunakan metode Jigsaw Learning. Untuk memahami permasalahan ini perlu kiranya dikaji melalui kegiatan Penelitian Tindakan Kelas (PTK) khususnya dengan menerapkan metode Jigsaw Learning di kelas. Secara lengkap penelitian tindakan kelas ini berjudul: "Peningkatan Prestasi Belajar Pendidikan Agama Islam Melalui Metode Jigsaw Learning Di Kelas V SD Negeri 0701 Rotan Sogo Tahun Pelajaran 2014/2015”.

\section{B. METODE PENELITIAN}

Penelitian dilaksanakan di Kelas V SD Negeri 0701 Rotan Sogo 2 Kecamatan Hutaraja Tinggi Kabupaten Padang Lawas dengan jumlah siswa sebanyak 33 siswa pada semester II tahun pelajaran 2014/2015. Penelitian dilaksanakan tanggal 13 Oktober 2014 untuk siklus I, dan pada tanggal 20 Oktober 2014 untuk siklus II dan dilanjutkan siklus III pada tanggal 27 Oktober 2014.

Mata pelajaran yang menjadi obyek penelitian adalah Pendidikan Agama Islam (PAI) sesuai dengan silabus pada saat penelitian ini dilaksanakan, maka pokok bahasan yang diambil adalah tentang puasa Ramadlan dan puasa sunah, Standar Kompetensi (SK) Mengenal puasa wajib, Kompetensi Dasar (KD):

1. Menyebutkan ketentuan-ketentuan puasa ramadlan

2. Menyebutkan hikmah puasa

Dengan indikator sebagai berikut:

a. Menjelaskan pengertian puasa Ramadhan

b. Menyebutkan ketentuan-ketentuan puasa Ramadhan 
c. Menjelaskan macam-macam amalan Ramadhan

d. Menyebutkan macam-macam hikmah puasa

e. Menjelaskan cara berpuasa Ramadhan dengan benar

Jumlah siswa kelas V SD Negeri 0701 Rotan Sogo yang dijadikan obyek penelitian ini adalah 33 siswa, terdiri dari 18 putra dan 15 putri. Karakteristik siswa kelas ini dapat digambarkan sebagai berikut:

1. Usia Siswa rata-rata 11 tahun

Latar belakang keluarga/orang tua mayoritas sebagai petani.

Tingkat kemampuan siswa, berdasarkan pengamatan selama peneliti mengajar adalah 8 siswa pandai, 15 siswa berkemampuan sedang dan 10 siswa lambat belajar

Siklus pertama penelitian ini dilaksanakan pada hari Selasa tanggal 13 Oktober 2014 dengan materi pokok ketentuan puasa Ramadlan dengan indikator menjelaskan pengertian puasa Ramadhan, menyebutkan ketentuan-ketentuan puasa Ramadhan. Tahapan dan langkah-langkah yang dilakukan peneliti adalah sebagai berikut:

Dalam tahapan perencanaan ini mencakup kegiatan sebagai berikut: 1) Instrumen yang digunakan adalah lembar soal dan buku Pendidikan Agama Islam untuk kelas V, LKS (lembar kerja siswa) untuk kelas V; 2) Penyiapan buku paket sebagai sumber pembelajaran Pendidikan Agama Islam.

Dalam pelaksanaan penelitian, peneliti bertindak sebagai pengajar. Adapun kegiatan pembelajaran mengacu pada rencana pembelajaran yang telah disiapkan.

Dalam post test ini digunakan cara yang sama dengan pre-test. Berikut prestasi belajar siswa pada siklus I: 
Tabel 1. Prestasi Belajar Siklus I

\begin{tabular}{|c|c|c|c|}
\hline NO & NILAI & KKM & KETERANGAN \\
\hline 1. & 8,2 & 6,50 & Tuntas \\
\hline 2. & 6,3 & 6,50 & Tidak tuntas \\
\hline 3. & 6,4 & 6,50 & Tidak tuntas \\
\hline 4. & 5,7 & 6,50 & Tidak tuntas \\
\hline 5. & 8,1 & 6,50 & Tidak tuntas \\
\hline 6. & 6,3 & 6,50 & Tidak tuntas \\
\hline 7. & 6,4 & 6,50 & Tidak tuntas \\
\hline 8. & 6 & 6,50 & Tidak tuntas \\
\hline 9. & 4,9 & 6,50 & Tidak tuntas \\
\hline 10. & 5,7 & 6,50 & Tidak tuntas \\
\hline 11. & 5,9 & 6,50 & Tidak tuntas \\
\hline 12. & 7,5 & 6,50 & Tuntas \\
\hline 13. & 6,4 & 6,50 & Tidak tuntas \\
\hline 14. & 7,4 & 6,50 & Tuntas \\
\hline 15. & 8,2 & 6,50 & Tuntas \\
\hline 16. & 8,4 & 6,50 & Tuntas \\
\hline 17. & 7,0 & 6,50 & Tuntas \\
\hline 18. & 6,0 & 6,50 & Tidak tuntas \\
\hline 19. & 7,2 & 6,50 & Tuntas \\
\hline 20. & 5,5 & 6,50 & Tidak tuntas \\
\hline 21. & 7,6 & 6,50 & Tuntas \\
\hline 22. & 9,0 & 6,50 & Tuntas \\
\hline 23. & 5,1 & 6,50 & Tidak tuntas \\
\hline 24. & 4,0 & 6,50 & Tidak tuntas \\
\hline 25. & 5,4 & 6,50 & Tidak tuntas \\
\hline 26. & 9,0 & 6,50 & Tuntas \\
\hline 27. & 5,5 & 6,50 & Tidak tuntas \\
\hline 28. & 7,0 & 6,50 & Tuntas \\
\hline
\end{tabular}




\begin{tabular}{|c|c|c|c|c|}
\hline \multicolumn{2}{|c|}{ o) bc } & \multicolumn{2}{|c|}{$\begin{array}{l}\text { Jurnal IImu-llmu Sosial dan } \\
\text { Keislaman }\end{array}$} & $\begin{array}{r}\text { Vol. } 2 \text { No. } 1 \\
\text { Januari - Juni } 20 \\
\end{array}$ \\
\hline & & & & \\
\hline NO & NILAI & KKM & KE & ANGAN \\
\hline 29. & 7,4 & 6,50 & & atas \\
\hline 30. & 4,2 & 6,50 & & tuntas \\
\hline 31. & 5,3 & 6,50 & & tuntas \\
\hline 32. & 4,1 & 6,50 & & tuntas \\
\hline 33. & 7,0 & 6,50 & & ntas \\
\hline
\end{tabular}

Observasi dilakukan untuk mengetahui penerapan metode jigsaw learning dalam meningkatkan prestasi belajar Pendidikan Agama Islam di kelas V. Untuk melakukan pengamatan terhadap situasi kelas pada saat pembelajaran, peneliti meminta bantuan guru untuk mengamati selama pembelajaran berlangsung.

Refleksi dilakukan oleh peneliti berdasarkan dari dua hasil penelitian, yaitu hasil pengamatan situasi kelas/pembelajaran dan hasil perbandingan/peningkatan nilai post test dibanding nilai pre-test. Pelaksanaan kegiatan pembelajaran pada siklus 1 ini masih terdapat kekurangan, karena dari 33 anak yang mendapat nilai di atas KKM baru 12 siswa sehingga perlu adanya revisi untuk dilakukan pada siklus berikutnya. Perbandingan nilai ketuntasan post-test terhadap pre-test menjadi dasar perbaikan pada siklus berikutnya.

Siklus kedua penelitian ini dilaksanakan pada hari Rabu tanggal 20 Oktober 2014 dengan materi pokok puasa ramadlan dengan indikator menjelaskan, menjelaskan macam-macam amalan Ramadhan.

Tabel 2. Prestasi belajar siswa siklus II

\begin{tabular}{|c|c|c|c|}
\hline No & Nilai & KKM & Keterangan \\
\hline 1. & 9,3 & 6,50 & Tuntas \\
\hline 2. & 6,1 & 6,50 & Tidak tuntas \\
\hline 3. & 6,0 & 6,50 & Tidak tuntas \\
\hline 4. & 5,0 & 6,50 & Tidak tuntas \\
\hline 5. & 8,1 & 6,50 & Tuntas \\
\hline 6. & 6,2 & 6,50 & Tidak tuntas \\
\hline
\end{tabular}


(5) beluaddib

\begin{tabular}{|c|c|c|c|}
\hline No & Nilai & KKM & Keterangan \\
\hline 7. & 7,0 & 6,50 & Tuntas \\
\hline 8. & 7,0 & 6,50 & Tuntas \\
\hline 9. & 5,5 & 6,50 & Tidak tuntas \\
\hline 10. & 7,5 & 6,50 & Tuntas \\
\hline 11. & 6,4 & 6,50 & Tidak tuntas \\
\hline 12. & 7,7 & 6,50 & Tuntas \\
\hline 13. & 6,4 & 6,50 & Tidak tuntas \\
\hline 14. & 7,9 & 6,50 & Tuntas \\
\hline 15. & 9,0 & 6,50 & Tuntas \\
\hline 16. & 8,5 & 6,50 & Tuntas \\
\hline 17. & 7,5 & 6,50 & Tuntas \\
\hline 18. & 6,3 & 6,50 & Tidak tuntas \\
\hline 19. & 7,6 & 6,50 & Tuntas \\
\hline 20. & 5,0 & 6,50 & Tidak tuntas \\
\hline 21. & 7,4 & 6,50 & Tuntas \\
\hline 22. & 9,2 & 6,50 & Tuntas \\
\hline 23. & 6,2 & 6,50 & Tidak tuntas \\
\hline 24. & 5,0 & 6,50 & Tidak tuntas \\
\hline 25. & 6,0 & 6,50 & Tidak tuntas \\
\hline 26. & 10,0 & 6,50 & Tuntas \\
\hline 27. & 6,2 & 6,50 & Tidak tuntas \\
\hline 28. & 8,3 & 6,50 & Tuntas \\
\hline 29. & 8,5 & 6,50 & Tuntas \\
\hline 30. & 5,7 & 6,50 & Tidak tuntas \\
\hline 31. & 6,1 & 6,50 & Tidak tuntas \\
\hline 32. & 4,5 & 6,50 & Tidak tuntas \\
\hline 33. & 8,0 & 6,50 & Tuntas \\
\hline
\end{tabular}

Peneliti dan mitra melakukan pengamatan terhadap proses pembelajaran dan nilai siswa setelah akhir kegiatan pembelajaran dari hasil evaluasi. 
Berdasarkan hasil pengamatan selama berlangsung pembelajaran terhadap situasi kelas dan prestasi siswa pelaksanaan kegiatan pembelajaran pada siklus II ini masih terdapat kekurangan, peneliti dapat menemukan kelemahan pembelajaran sebagai berikut:

Siswa yang berkemampuan rendah masih kurang aktif dalam meringkas materi pelajaran dan dalam kelompok terlihat banyak diam selama kegiatan berlangsung.

Ada kelompok yang tidak berani menjelaskan ke kelompok lain karena malu.

Perbandingan nilai hasil past test dengan pre-test menunjukkan masih ada kelemahan, sehingga akan dilakukan perbaikan pada siklus III

Siklus ketiga penelitian ini dilaksanakan pada hari Selasa tanggal 27 Oktober 2014 dengan materi pokok ketentuan-ketentuan puasa ramadlan, menjelaskan tata cara puasa ramadlan dengan benar. Dalam siklus ketiga peneliti melakukan perbaikan pembelajaran dengan pembentukan kelompok dengan mengadakan perubahan anggota kelompok yang aktif ke kelompok yang pasif.

Tabel 3. Prestasi belajar pada siklus III

\begin{tabular}{|c|c|c|c|}
\hline No & Nilai & KKM & Keterangan \\
\hline 1. & 10,0 & 6,50 & Tuntas \\
\hline 2. & 7,0 & 6,50 & Tuntas \\
\hline 3. & 8,1 & 6,50 & Tuntas \\
\hline 4. & 7,2 & 6,50 & Tuntas \\
\hline 5. & 10,0 & 6,50 & Tuntas \\
\hline 6. & 8,0 & 6,50 & Tuntas \\
\hline 7. & 8,2 & 6,50 & Tuntas \\
\hline 8. & 9,1 & 6,50 & Tuntas \\
\hline 9. & 7,3 & 6,50 & Tuntas \\
\hline 10. & 9,0 & 6,50 & Tuntas \\
\hline 11. & 8,1 & 6,50 & Tuntas \\
\hline
\end{tabular}




\begin{tabular}{|c|c|c|c|}
\hline bs lluaa & \multicolumn{2}{|c|}{$\begin{array}{c}\text { Jurnal IImu-IImu Sosial dan } \\
\text { Keislaman }\end{array}$} & $\begin{aligned} \text { Vol. } 2 \text { No. } 1 \\
\text { Januari - Juni } 20 \\
\end{aligned}$ \\
\hline \multicolumn{4}{|l|}{ E } \\
\hline No & Nilai & KKM & Keterangan \\
\hline 12. & 8,3 & 6,50 & Tuntas \\
\hline 13. & 8,1 & 6,50 & Tuntas \\
\hline 14. & 9,2 & 6,50 & Tuntas \\
\hline 15. & 10,0 & 6,50 & Tuntas \\
\hline 16. & 9,3 & 6,50 & Tuntas \\
\hline 17. & 9,3 & 6,50 & Tuntas \\
\hline 18. & 8,2 & 6,50 & Tuntas \\
\hline 19. & 9,0 & 6,50 & Tuntas \\
\hline 20. & 6,3 & 6,50 & Tidak tuntas \\
\hline 21. & 9,0 & 6,50 & Tuntas \\
\hline 22. & 10,0 & 6,50 & Tuntas \\
\hline 23. & 8,3 & 6,50 & Tuntas \\
\hline 24. & 6,4 & 6,50 & Tidak tuntas \\
\hline 25. & 8,3 & 6,50 & Tuntas \\
\hline 26. & 10,0 & 6,50 & Tuntas \\
\hline 27. & 8,3 & 6,50 & Tuntas \\
\hline 28. & 10,0 & 6,50 & Tuntas \\
\hline 29. & 9,2 & 6,50 & Tuntas \\
\hline 30. & 5,0 & 6,50 & Tidak tuntas \\
\hline 31. & 8,3 & 6,50 & Tuntas \\
\hline 32. & 5,7 & 6,50 & Tidak tuntas \\
\hline 33. & 9,0 & 6,50 & Tuntas \\
\hline $\mathrm{Jml}$ & 277 & & \\
\hline Rata- rata & 8,44 & & \\
\hline
\end{tabular}

Sesuai dengan tujuan penelitian ini yaitu untuk meningkatkan prestasi belajar Pendidikan Agama Islam (PAI) tentang ketentuanketentuan puasa ramadlan, maka pengamatan difokuskan pada upaya peningkatan prestasi belajar. Seperti pada siklus sebelumnya untuk 


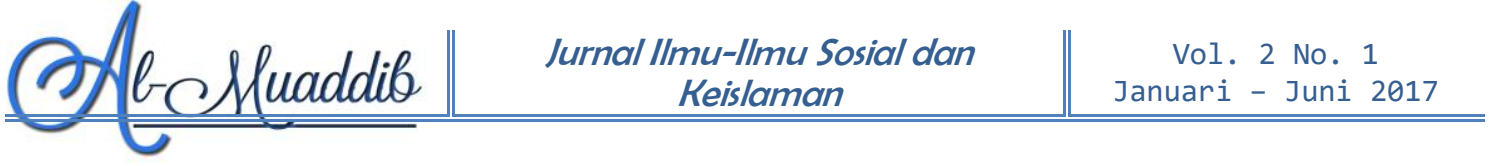

melakukan pengamatan terhadap situasi kelas pada saat pembelajaran, peneliti meminta bantuan teman sejawat untuk mengamati selama pembelajaran berlangsung.

Berdasarkan hasil pengamatan selama berlangsung pembelajaran terhadap situasi kelas dan prestasi siswa pelaksanaan kegiatan pembelajaran pada siklus III.

Pada siklus III guru telah menerapkan metode pembelajaran Jigsaw learning dengan baik dilihat dari aktifitas siswa, perhatian serta keaktifan terhadap pembelajaran sudah mengalami peningkatan. Maka tidak perlu dilakukan revisi terlalu banyak, tetapi yang perlu diperhatikan untuk tindakan selanjutnya adalah memaksimalkan dan mempertahankan apa yang telah ada dengan tujuan agar pelaksanaan proses pembelajaran selanjutnya dengan metode jigsaw learning dapat meningkatkan proses pembelajaran sehingga tujuan pembelajaran dapat tercapai.

\section{HASIL dan PEMBAHASAN}

Untuk mengukur keberhasilan siswa dalam mengikuti pelajaran, pada kegiatan akhir peneliti mengadakan evaluasi. Adapun hasil evaluasi tersebut dapat dilihat dalam rekapitulasi nilai persiklus dalam tabel sebagai berikut:

Tabel 4. Rekapitulasi prestasi belajar siswa

\begin{tabular}{|c|c|c|c|}
\hline \multirow{2}{*}{ No. } & \multicolumn{3}{|c|}{ Nilai } \\
\cline { 2 - 4 } & Siklus I & Siklus II & Siklus III \\
\hline 1. & 8,2 & 9,3 & 10,0 \\
\hline 2. & 6,3 & 6,1 & 7,0 \\
\hline 3. & 6,4 & 6,0 & 8,1 \\
\hline 4. & 5,7 & 5,0 & 7,2 \\
\hline 5. & 8,1 & 8,1 & 10,0 \\
\hline 6. & 6,3 & 6,2 & 8,0 \\
\hline 7. & 6,4 & 7,0 & 8,2 \\
\hline
\end{tabular}


Stectuaddib.

\begin{tabular}{|c|c|c|c|}
\hline \multirow{2}{*}{ No. } & \multicolumn{3}{|c|}{ Nilai } \\
\hline & Siklus I & Siklus II & Siklus III \\
\hline 8. & 6 & 7,0 & 9,1 \\
\hline 9. & 4,9 & 5,5 & 7,3 \\
\hline 10. & 5,7 & 7,5 & 9,0 \\
\hline 11. & 5,9 & 6,4 & 8,1 \\
\hline 12. & 7,5 & 7,7 & 8,3 \\
\hline 13. & 6,4 & 6,4 & 8,1 \\
\hline 14. & 7,4 & 7,9 & 9,2 \\
\hline 15. & 8,2 & 9,0 & 10,0 \\
\hline 16. & 8,4 & 8,5 & 9,3 \\
\hline 17. & 7,0 & 7,5 & 9,3 \\
\hline 18. & 6,0 & 6,3 & 8,2 \\
\hline 19. & 7,2 & 7,6 & 9,0 \\
\hline 20. & 5,5 & 5,0 & 6,3 \\
\hline 21. & 7,6 & 7,4 & 9,0 \\
\hline 22. & 9,0 & 9,2 & 10,0 \\
\hline 23. & 5,1 & 6,2 & 8,3 \\
\hline 24. & 4,0 & 5,0 & 6,4 \\
\hline 25. & 5,4 & 6,0 & 8,3 \\
\hline 26. & 9,0 & 10,0 & 10,0 \\
\hline 27. & 5,5 & 6,2 & 8,3 \\
\hline 28. & 7,0 & 8,3 & 10,0 \\
\hline 29. & 7,4 & 8,5 & 9,2 \\
\hline 30. & 4,2 & 5,7 & 5,0 \\
\hline 31. & 5,3 & 6,1 & 8,3 \\
\hline 32. & 4,1 & 4,5 & 5,7 \\
\hline 33. & 7,0 & 8,0 & 9,0 \\
\hline Jumlah & 214 & 231 & 277 \\
\hline Rata-rata & 6,49 & 7,0 & 8,44 \\
\hline
\end{tabular}




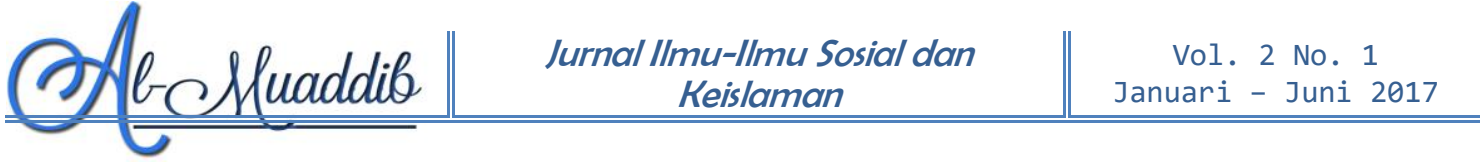

Untuk mengukur keberhasilan siswa dalam mengikuti pelajaran, pada kegiatan akhir peneliti mengadakan evaluasi. Pada pelaksanaan pembelajaran siklus I hasil evaluasi menunjukkan peningkatan. Dari 33 siswa ada 14 siswa yang memperoleh nilai 6,50 ke atas. Rata-rata kelas 6,49. ketuntasan belajar 42,4\%. Dari data tersebut dapat dilihat bahwa 33 siswa masih ada 19 siswa yang belum tuntas belajar. Hal ini disebabkan oleh beberapa kemungkinan seperti dibawah ini:

1. Peneliti dalam menggunakan metode secara monoton sehingga siswa merasa jenuh.

2. Proses pembelajaran didominasi oleh guru sehingga siswa kurang aktif dalam proses pembelajaran.

3. Untuk mengatasi kelemahan-kelemahan tersebut peneliti harus memperbaiki pada kinerja siklus II. Bentuk perbaikan ditempuh dengan menerapkan metode jigsaw learning.

Setelah dilaksanakan perbaikan pembelajaran siklus II, hasil evaluasi menunjukkan peningkatan dari perbaikan pembelajaran siklus I. Pada pelaksanaan pembelajaran siklus I, dari 33 siswa hanya 14 siswa yang memperoleh nilai 7 keatas. Setelah dilaksanakan perbaikan pada siklus II hasil evaluasi menunjukkan peningkatan. Dari 33 siswa ada 17 siswa yang memperoleh nilai 7,0 ke atas. Rata-rata kelas yang semula 6,49 menjadi 7,0. Sedangkan ketuntasan belajar semula $42,4 \%$ menjadi $63,6 \%$.

Ketuntasan belajar mencapai $63,6 \%$ sedangkan semula $42,4 \%$, atau mengalami kenaikan $21,2 \%$ sedangkan nilai rata-rata kelas menjadi 7,0. Pengubahan strategi yang dilakukan guru mampu meningkatkan prestasi belajar siswa. Masih ada 16 siswa yang belum tuntas belajarnya. Peneliti memberikan bimbingan khusus kepada 16 siswa tersebut.

Setelah dilaksanakan pembelajaran siklus III, hasil evaluasi menunjukkan peningkatan dari pembelajaran siklus III. Dari 33 siswa, ada 29 siswa yang berhasil mencapai ketuntasan belajar, rata-rata 
kelas 8,24 hasil evaluasi pada siklus III menunjukkan peningkatan. Dari 33 siswa ada 29 siswa berhasil mencapai ketuntasan belajar. Ketuntasan belajar mencapai $87,9 \%$ sedangkan semula $67,7 \%$, atau mengalami kenaikan 20,2\% sedangkan nilai rata-rata kelas menjadi 8,24 . Pengubahan strategi yang dilakukan guru mampu meningkatkan prestasi belajar siswa. Masih ada 4 siswa yang belum tuntas belajarnya. Peneliti memberikan bimbingan khusus kepada 4 siswa tersebut.

\section{Tabel 5. Ketuntasan Belajar Siswa Siklus I, Siklus II dan Siklus III}

\begin{tabular}{|c|c|c|c|c|c|c|c|}
\hline \multirow{2}{*}{ Nilai } & \multicolumn{4}{|c|}{ Banyaknya siswa } & \multicolumn{2}{c|}{ Persentase } & \multirow{2}{*}{ Ket } \\
\cline { 2 - 6 } & Siklus & Siklus & Siklus & Siklus I & Siklus & Siklus & II \\
\cline { 2 - 6 } & I & II & III & III & \\
\hline$<6,50$ & 19 & 16 & 4 & $57,6 \%$ & $48,5 \%$ & $12,1 \%$ & $\begin{array}{c}\text { Tidak } \\
\text { tuntas }\end{array}$ \\
\hline$\geq 6,50$ & 14 & 17 & 29 & $42,4 \%$ & $51,5 \%$ & $87,9 \%$ & Tuntas \\
\hline $\begin{array}{c}\text { Rata-rata } \\
\text { Kelas }\end{array}$ & 6,49 & 7,0 & 8,44 & - & - & - & - \\
\hline
\end{tabular}

Dari tabel di atas dapat disimpulkan bahwa setelah dilakukan perbaikan dari siklus I yang tidak tuntas dari 19 siswa menjadi 16 siswa pada siklus II, dan menjadi 4 siswa pada siklus III. Siswa yang tuntas meningkat dari siklus I dari 14 menjadi 17 pada siklus II (meningkat 3) dan meningkat lagi menjadi 29 siswa pada siklus III (meningkat 12 siswa). Hasil evaluasi Pembelajaran Pendidikan Agama Islam adalah:

1. Pada siklus I ketuntasan belajar siswa hanya mencapai 42,4\%,

2. pada pelaksanaan siklus II ketuntasan belajar menjadi 51,5\%.

3. Sedangkan pada pelaksanaan siklus III meningkat lagi menjadi $87,9 \%$ 


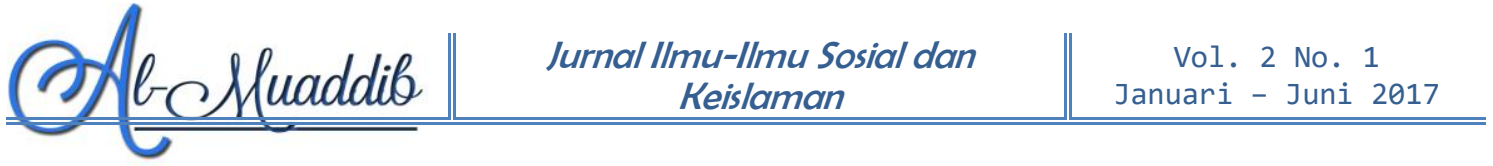

4. Per Siklus Pembelajaran Pendidikan Agama Islam (PAI) pada pelaksanaan siklus I nilai rata-rata hanya mencapai 6,49 pada pelaksanaan siklus II meningkat menjadi 7,0 dan pada pelaksanaan siklus III nilai rata-rata meningkat lagi menjadi 8,44 .

Perbaikan pembelajaran siklus I yang difokuskan pada penjelasan materi macam-macam puasa menurut hukumnya dengan menggunakan metode jigsaw learning. Nilai rata-rata siswa 6,49. Hal ini menunjukkan bahwa kegiatan pembelajaran belum mencapai KKM dan pada siklus berikutnya harus diperbaiki.

Pada perbaikan pembelajaran siklus II nilai rata-rata siswa dan tingkat pencapaian ketuntasan belajar meningkat. Nilai rata-rata siswa meningkat dari 6,49 menjadi 7,0. Tingkat ketuntasan belajar meningkat dari 42,4\% menjadi 51,5\%. Peningkatan prestasi belajar siswa dapat tercapai karena guru dengan melaksanakan perbaikan pembelajaran dengan baik.

Melalui perbaikan pembelajaran Pendidikan Agama Islam (PAI) yang dilaksanakan dalam siklus ini, pemahaman siswa tentang pembelajaran ketentuan-ketentuan puasa ramadlan dapat ditingkatkan. Pemahaman siswa terhadap materi pelajaran meningkat karena peneliti selaku guru melaksanakan seluruh kegiatan perbaikan yang telah direncanakan dengan sungguh-sungguh.

Pada perbaikan pembelajaran siklus III nilai rata-rata siswa dan tingkat pencapaian ketuntasan belajar meningkat. Nilai rata-rata siswa meningkat dari 7,0 menjadi 8,44. Tingkat ketuntasan belajar meningkat dari 51,5\%. menjadi 87,9\%. Dari 33 siswa masih ada 4 siswa yang tidak tuntas KKM. Hal ini disebabkan faktor dari diri siswa yang hiperaktif, tidak memperhatikan pembelajaran serta serimg tidak masuk dengan berbagai alasan.

Sebanyak 29 siswa tuntas KKM atau 87,9\% mencapai ketuntasan belajar, prestasi belajar siswa meningkat. Peningkatan prestasi belajar 
siswa dapat tercapai karena guru dengan melaksanakan perbaikan pembelajaran dengan baik. Melalui perbaikan pembelajaran Pendidikan Agama Islam (PAI) yang dilaksanakan dalam siklus ini, pemahaman siswa tentang pembelajaran khikmah puasa dapat ditingkatkan. Pemahaman siswa terhadap materi pelajaran meningkat karena peneliti selaku guru melaksanakan seluruh kegiatan perbaikan yang telah direncanakan dengan sungguh-sungguh.

\section{SIMPULAN}

Dari hasil kegiatan pembelajaran dengan menerapkan metode jigsaw learning yang telah dilakukan selama tiga siklus, dapat disimpulkan bahwa Pembelajaran dengan menerapkan metode jigsaw learnng memiliki dampak positif dalam meningkatkan prestasi belajar siswa dengan nilai rata-rata 6,49 pada siklus I, menjadi 7,00 pada siklus II dan meningkat lagi menjadi 8,44 pada siklus III. Keberhasilan proses pembelajaran ditandai dengan peningkatan ketuntasan belajar siswa dalam setiap siklus, yaitu siklus I $(42,4 \%)$, siklus II $(51,5 \%)$ siklus III $(87,9 \%)$.

\section{E. SARAN}

Dari hasil penelitian yang diperoleh dari uraian sebelumnya agar proses belajar mengajar Pendidikan Agama Islam (PAI) lebih efektif dan lebih memberikan hasil yang optimal bagi siswa, maka peneliti memiliki saran sebagai berikut:

1. Guru Pendidikan Agama Islam (PAI) untuk dapat secara kreatif mencobakan dan mengembangkan model pembelajaran tersendiri yang khas, sesuai dengan kondisi nyata di tempat kerja masingmasing, sehingga pada gilirannya akan muncul model-model pembelajaran versi guru yang bersangkutan, yang tentunya semakin memperkaya khazanah model pembelajaran yang telah ada. 
2. Guru harus dapat menjaga dan membina keterlibatan aktif siswa dalam kegiatan pembelajaran agar daya serap anak terhadap materi yang diberikan guru menjadi lebih mantap.

3. Kepada Kepala Sekolah untuk dapat senantiasa memotivasi guru-guru di sekolah agar mengembangkan profesionalitasnya sebagai pendidik.

\section{DAFTAR PUSTAKA}

Al-Mundziri,1994. Ringkasan Hadits Shahih Muslim. Jakarta: Pustaka Imani

Arikuto, Suharsimi, 2007. Penelitian Tindakan Kelas: Bumi Aksara Penelitian Tindakan Kelas. Jakarta: Bumi Aksara

Bahri Djamarah, Syaiful. 1994.Guru dan Anak Didik dalam Interaksi Edukatif. Bandung: Rineka Cipta.

Hamalik, Oemar. 2010. Psikologi Belajar. Bandung: PT Sinar Baru Algesindo

Khairudin.2007. Kurikulum Tingkat Satuan Pendidikan. Jogjakarta: Nuansa Aksara.

Jamaludin, 2002.Pembelajaran yang Efektif. Jakarta; Departemen Agama RI

Purwanto, M. Ngalim.2003. Psikologi Pendidikan, Bandung: PT Remaja Rosda Karya.

Slameto, 2001. Belajar dan Faktor-Faktor yang Mempengaruhinya. Jakarta: Bumi Aksara.

S.M, Ismail.2008. Strategi Pembelajaran Agama Islam Berbasis PAIKEM. Semarang: Rasail Media Group.

Surya Brata, Sumadi,1993. Psikologi Pendidikan, Jakarta: Raja Grafindo Persada

Sumiati, 2008. Metode Pembelajaran (Seri Pembelajaran Efektif) Bandung: CV Wacana Prima

Syah, Muhibin. 1999.Psikologi Belajar. Jakarta: PT Logos Wacana Ilmu 